\title{
Hypersensitivity Reactions to Nonsteroidal Anti-Inflammatory Drugs among Adults: Clinical Features and Risk Factors for Diagnosis Confirmation
}

\author{
Eva Rebelo Gomes ${ }^{\mathrm{a}}$ Luísa Geraldes ${ }^{\mathrm{b}}$ Ângela Gaspar ${ }^{\mathrm{c}}$ Daniela Malheiro ${ }^{\mathrm{d}}$ \\ Susana Cadinhad $^{d}$ Carmo Abreu $^{a}$ Marta Chambel $^{c}$ Eugénia Almeida ${ }^{\mathrm{e}}$ \\ Emília Faria ${ }^{e}$ Portuguese Society of Allergology and Clinical Immunology \\ (SPAIC) Drug Allergy Interest Group
}

\begin{abstract}
a Immunoallergology Department, Centro Hospitalar do Porto EPE, Porto, ${ }^{\mathrm{b}}$ Immunoallergology Department, Hospital Sr ${ }^{a}$ da Oliveira EPE, Guimarães, ' Immunoallergology Department, CUF Descobertas Hospital, Lisbon, dImmunoallergology Department, Centro Hospitalar Gaia-Espinho EPE, Vila Nova de Gaia, and ${ }^{\mathrm{e}}$ Immunoallergology Department, Coimbra University Hospital Center EPE, Coimbra, Portugal
\end{abstract}

\section{Keywords}

Drug hypersensitivity · Drug allergy · Nonsteroidal

anti-inflammatory drugs $\cdot$ Phenotypes $\cdot$ Risk factors $\cdot$ Clinical investigation · Diagnostic workup - Drug provocation tests

\footnotetext{
Abstract

Background: Nonsteroidal anti-inflammatory drugs (NSAIDS) are among the most common causes of drug hypersensitivity (HS) reactions. The diagnosis is based on a careful clinical history, and provocation tests are considered the gold standard for diagnosis. Skin tests have some value to study reactions to pyrazolones. Laboratory investigations are mostly used for research purposes. Different phenotypes have been described. Objective and Methods: Our aim was to describe the most common clinical manifestations of NSAID HS in a large population of adult patients, the drugs involved, the association with previously described risk factors, and the outcome of diagnostic procedures. The classification of reactions proposed by the European Academy of
}

Allergy and Clinical Immunology (EAACI) Drug Allergy Interest Group was adopted. Results: Acetylsalicylic acid was the drug most often involved in reactions (34\%), isolated cutaneous symptoms were the most reported (60\%), and immediate reactions (58\%) were the most common. There was an overall female predominance (64\%) and $35 \%$ of the patients were atopic. HS to NSAIDs was confirmed in $21 \%$ of the patients. The most common phenotypes encountered among HS patients were NSAID-induced urticaria/angioedema and single-NSAID-induced urticaria/angioedema or anaphylaxis. Logistic regression analysis showed that gender and atopy were not significant risk factors for HS confirmation, but diagnosis depended on the number of previous reactions, the type of reaction, and the time interval between drug intake and reaction. Conclusion: Only $21 \%$ of suspected HS reactions were confirmed after diagnostic workup. Patients describing $>1$ previous reaction and suffering immediate reactions had a higher probability of a positive investigation.

(c) 2017 S. Karger AG, Basel

\section{KARGER}

(c) 2017 S. Karger AG, Basel 


\section{Introduction}

Nonsteroidal anti-inflammatory drugs (NSAIDs) are an important class of drugs with several therapeutic applications. From the classical aspirin (acetylsalicylic acid), on the market since 1899 , to the more recently developed selective COX-2 inhibitors, NSAIDs are widely used to treat pain and fever and are available as over-the-counter drugs in many countries. NSAIDs are well-recognized as a cause of adverse drug reactions in general [1], and are also the second-most reported cause of drug hypersensitivity (HS) reactions after betalactam antibiotics (BL) [2], and even constitute the first cause according to certain recent studies [3-5]. The reported NSAID HS prevalence ranges from 0.6 to $2.5 \%$ in the general population, being higher among females, patients with chronic urticaria, and asthmatics [6-11]. Atopy has also been described as a risk factor for NSAID HS $[5,12,13]$.

Previous Portuguese population studies on the prevalence of drug HS found that $8 \%$ of adults and $6 \%$ of children self-reported allergy to at least one drug, with NSAIDs being the second-most suspected $[14,15]$. In a recent Portuguese study on drug-induced anaphylaxis, NSAIDs were the most frequent culprits [16].

Different classification of reactions to NSAIDs and phenotypes have been described over the last decades based on clinical presentation, culprit drugs, onset of reactions and preexisting respiratory or cutaneous diseases [11, 17-21]. An updated classification of reactions was published in a consensus paper by the European Academy of Allergy and Clinical Immunology (EAACI) in 2013 [22], and we adopted it in this work. This classification considers 2 main groups of reactions and refers to 5 different phenotypes (Table 1).

The clinical workup of patients with NSAID HS and their classification requires substantial resources as it relies mostly on a detailed clinical history and on drug provocation tests (DPTs), considered to be the gold standard for diagnosis. Thus, trained personnel and an appropriate hospital setting are necessary in order to minimize the risks for patients $[23,24]$.

\section{Material and Methods}

Patients with a suggestive clinical history of NSAID HS attending specialized drug allergy clinics from 5 national participating centers were enrolled during 2013. They were sequentially, retrospectively, and anonymously included in a standardized online database by the attending allergist after the conclusion of diagnostic
Table 1. Classification of HS to NSAIDs

Nonimmunologically mediated (cross-reactive) HS reactions to NSAIDs

NERD

NECD

NIUA

Immunologically mediated (non-cross-reactive) HS reactions to NSAIDs

SNIUAA

SNIDR (24-48 h after drug administration)

Adapted from Kowalski et al. [22].

Table 2. Characterization of the population

$\begin{array}{ll}\begin{array}{l}\text { Total number of patients } \\ \text { Age }\end{array} & 227 \\ \quad \text { Mean } \pm \text { SD } & 47 \pm 14 \text { years } \\ \quad \text { Range } & 18-79 \text { years } \\ \text { Males/females } & 82(36 \%) / 145(64 \%) \\ \text { Previous diagnosis of asthma/rhinitis } & 97(43 \%) \\ \text { Previous diagnosis of chronic urticaria } & 20(9 \%) \\ \text { Atopy } & 80(35 \%) \\ \text { HS to drugs other than NSAIDs } & 69(30 \%)\end{array}$

procedures. Patients with isolated gastrointestinal symptoms or vague complaints were excluded.

Two hundred and twenty-seven patients aged 18-79 years (mean age $47 \pm 14$ years), $64 \%$ of whom were female, were evaluated. Their personal history of atopy, asthma/rhinitis, chronic urticaria, and reported HS to other drugs other than NSAIDs were recorded (Table 2). For the definition of anaphylaxis, we adopted the criteria issued by the second Symposium on the Definition and Management of Anaphylaxis [25]. For grading anaphylactic reactions, we used the criteria proposed by the EAACI [26].

Atopy was defined as a positive skin prick test result to at least 1 of the usually tested aeroallergens or a positive test to the inhalant, Phadiatop ${ }^{\circledR}$ (ImmunoCAP ${ }^{\circledR}$, Thermo Fisher, Uppsala, Sweden).

The clinical characteristics of the first reaction were registered. Reactions were also classified as immediate and nonimmediate according to the time that elapsed from the last drug intake (i.e. occurring $<1 \mathrm{~h}$ or $>1 \mathrm{~h}$ after drug administration).

Skin tests (STs) with pyrazolones were performed according to international guidelines with a nondiluted solution for the prick test and $0.1 \mathrm{mg} / \mathrm{mL}$ as a maximum nonirritating concentration for the intradermal test [27].

A single-blind, placebo-controlled oral challenge was the common practice. DPTs were performed at least 4 weeks after the most recent adverse reaction in the hospital setting by experienced personnel with available emergency equipment. Patients did not have cutaneous or respiratory symptoms or uncontrolled illnesses at the time of the DPTs. During the procedure, symptoms or signs, vital parameters, and forced expiratory volume in $1 \mathrm{~s}\left(\mathrm{FEV}_{1}\right)$ or peak 
Fig. 1. Percentage of positive diagnostic investigations for the 5 most frequently suspected NSAID pharmacological groups.

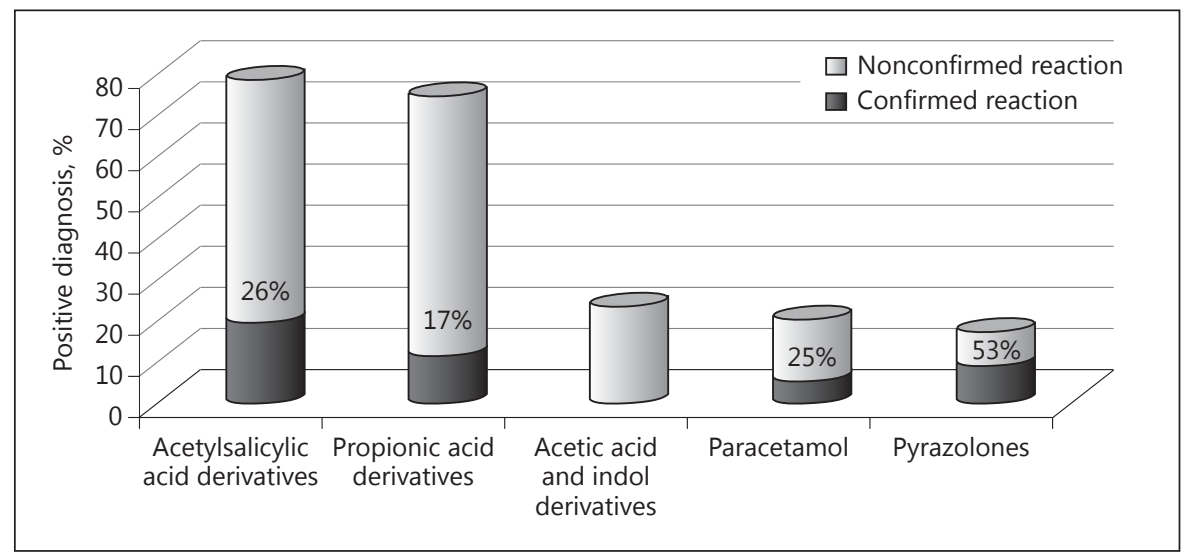

expiratory flow were assessed (in the case of previous respiratory disease or a reaction). NSAIDs were administered at 1-h intervals until the usual daily dose was achieved or symptoms appeared. The test was considered positive if the patient developed objective cutaneous and/or respiratory symptoms or $\mathrm{FEV}_{1} /$ peak expiratory flow decreased at least $20 \%$ from its initial value. Contraindications to DTPs based on a previous EAACI consensus paper were respected [22-24]. A written informed consent was signed by patients before performing an ST or a DPT, according to each center's usual local practice.

\section{Statistical Analysis}

Categorical variables are presented as frequencies and percentages, and continuous variables as means and standard deviations. The independent $t$ test was used to evaluate continuous variables and the $\chi^{2}$ test or the Fisher exact test for qualitative variables. A stepwise binary logistic regression analysis was used to test the considered predictors of NSAID HS among patients with conclusive results. Potential confounding factors were adjusted. Reported $p$ values are 2 -tailed, with $p<0.05$ indicating statistical significance. All statistical tests were performed using SPSS v22.0.

\section{Results}

From the 227 patients included, 80 (35\%) were atopic, 97 (43\%) had a previous diagnosis of asthma and/or rhinitis, 20 (9\%) had chronic urticaria, and HS reactions were attributed to other drugs in 30\%, mostly BL (14\%) (Table 2).

The age range of patients at the first described reaction was $1-73$ years (mean age $35 \pm 17$ years). Seventy patients (31\%) reported 1 previous reaction, 62 (27\%) reported 2 reactions, $67(30 \%)$ reported $\geq 3$ reactions and 28 did not recall the exact number of reactions.

In 78 cases (34\%), acetylsalicylic acid (acetylsalicylic acid in 62 and lysine acetylsalicylate in 16) was the suspected drug involved in the first reaction. Propionic acid derivatives followed with 63 cases (28\%), i.e. ibuprofen
Table 3. NSAIDs assumed to be the cause for the initial adverse reaction

\begin{tabular}{lcc}
\hline & $n$ & $\%$ \\
\hline Acetylsalicylic acid & 78 & 34 \\
Propionic acid derivatives & 63 & 28 \\
Acetic acid and indol derivatives & 23 & 10 \\
Paracetamol & 20 & 9 \\
Pyrazolones & 17 & 7 \\
Nimesulide & 16 & 7 \\
Oxicams & 4 & 2 \\
Selective COX-2 inhibitors & 2 & 1 \\
Not recalled by the patient & 4 & 2
\end{tabular}

(56), naproxen (4), ketoprofen (2), and desketoprofen (1). Acetic acid and indol derivatives were implicated in 23 cases (10\%), i.e. diclofenac (22), and aceclofenac (1), and paracetamol was suspected to be involved in 20 cases (9\%) (Table 3).

The percentages of diagnostic confirmation for the 5 most frequent NSAIDs involved in the first reaction are shown in Figure 1. The clinical manifestations in the first episode included urticaria/angioedema in 136 cases $(60 \%)$, and systemic reaction/anaphylaxis in 52 patients (23\%) including 12 grade 3 anaphylactic reactions. Isolated respiratory symptoms occurred in 10 patients (4\%), cutaneous and respiratory symptoms were described by 26 patients $(11 \%)$, and 3 patients could not exactly recall their symptoms.

Most of the reactions, 132 (58\%), developed up to $1 \mathrm{~h}$ after drug intake, and 87 reactions (38\%) occurred later than $1 \mathrm{~h}$ after intake (in $11 \%,>24 \mathrm{~h}$ from last intake). In the remaining cases, the patients did not recall the exact timing of the reaction. 
Table 4. Positive DPTs with the culprit drug $(n=32)$ and with an alternative drug $(n=8)$

\begin{tabular}{lllll}
\hline & Culprit & & \multicolumn{2}{c}{ Alternative } \\
\hline Nimesulide & $n=8$ & $25.0 \%$ & $n=5$ & $62.5 \%$ \\
Acetylsalicylic acid & $n=7$ & $22.0 \%$ & & \\
Paracetamol & $n=6$ & $19.0 \%$ & & \\
Propionic acid derivatives & $n=4$ & $12.5 \%$ & & \\
Oxicams & $n=3$ & $9.0 \%$ & $n=3$ & $37.5 \%$ \\
Others & $n=4$ & $12.5 \%$ & & \\
\hline
\end{tabular}

Table 5. Characteristics of patients with NSAID HS confirmed or excluded

\begin{tabular}{|c|c|c|c|}
\hline & HS & No HS & $p$ value \\
\hline Total number of patients & $48(21)$ & $63(28)$ & \\
\hline Age, years & $46 \pm 12$ & $45 \pm 15$ & 0.75 \\
\hline \multicolumn{4}{|l|}{ Sex } \\
\hline Male & $18(16.4)$ & $20(18.2)$ & \multirow[t]{2}{*}{0.57} \\
\hline Female & $30(27.3)$ & $42(38.2)$ & \\
\hline \multicolumn{4}{|l|}{ Type of reaction } \\
\hline Urticaria/angioedema & $25(22.7)$ & $53(48.2)$ & \multirow{4}{*}{$<0.001$} \\
\hline Anaphylaxis & $18(16.4)$ & $3(2.7)$ & \\
\hline $\begin{array}{l}\text { Urticaria/angioedema and } \\
\text { respiratory symptoms }\end{array}$ & $4(3.6)$ & $3(2.7)$ & \\
\hline Respiratory symptoms & $1(0.9)$ & $3(2.7)$ & \\
\hline \multicolumn{4}{|l|}{ Time to the reaction } \\
\hline Immediate $(\leq 1 \mathrm{~h})$ & $40(36.7)$ & $18(16.5)$ & \multirow[t]{2}{*}{$<0.001$} \\
\hline Nonimmediate $(>1 \mathrm{~h})$ & $8(7.3)$ & $43(39.4)$ & \\
\hline Number of episodes & $2.4 \pm 1.2$ & $1.7 \pm 1.0$ & $<0.01$ \\
\hline \multicolumn{4}{|l|}{ Atopy } \\
\hline Yes & $14(12.6)$ & $21(18.9)$ & \multirow[t]{2}{*}{0.64} \\
\hline No & $34(30.6)$ & $42(37.8)$ & \\
\hline \multicolumn{4}{|c|}{ Reactions to other drugs classes } \\
\hline Antibiotics & $9(23.1)$ & $20(51.3)$ & \multirow[t]{2}{*}{0.70} \\
\hline Others & $4(10.3)$ & $6(15.4)$ & \\
\hline
\end{tabular}

Values are expressed as $n(\%)$ or mean \pm SD.

STs with the suspected pyrazolones were performed in $10 / 17$ patients for whom these drugs were the assumed culprits. STs were positive in 8 patients, who were then subjected to a DPT with an alternative NSAID. The remaining 2 patients, with a negative ST, were subjected to a DPT with the suspected drug, which was negative. One patient had a DPT with no previous ST, and this was positive. Six patients, who already had a known tolerance to alternative NSAIDs, did not undergo ST or a DPT, and were classified as nonconclusive.

Twenty-two subjects $(9.7 \%)$, including the 6 referred from the pyrazolone group, had contraindications or re- fused the DPT, as they already had a known alternative drug. In this group of patients, the workup was considered nonconclusive as HS could not be confirmed or ruled out. The remaining 205 patients were subjected to DPTs with the culprit or with an alternative drug.

DPTs with the culprit drug were performed on 95 patients and were negative in $63(66 \%)$, i.e. ruling out the HS diagnosis, and positive in $32(34 \%)$, i.e. confirming the diagnosis. One patient from the pyrazolone group underwent DPT with a suspect drug with no previous ST, with a positive result, thus confirming the diagnosis.

In these patients, nimesulide led to a positive DPT in 8 patients, acetylsalicylic acid in 7, paracetamol in 6, propionic acid derivatives in 4 (ibuprofen in 3 ), and meloxicam was involved in 3 positive provocations (Table 4 ).

DPTs with an alternative drug were performed in 110 patients and were positive in $8(7 \%)$, i.e. confirming NSAID HS (5 with nimesulide and 3 with meloxicam), and negative in 102 (93\%) (Table 4).

None of the 40 patients with a positive DPT experienced anaphylaxis, and their reactions were mild and controlled by symptomatic treatment. Reactions reproduced previously described ones in $63 \%$ of the patients. There was a fair agreement between the initial clinical manifestations of HS and the DPT-induced reactions with the Cohen $\kappa$ coefficient of $0.27(p<0.001)$ [28].

NSAID HS was confirmed in 48 patients, in 8 by a positive ST with pyrazolones and in 40 by a DTP, and was ruled out in 63 patients. Concerning the reaction onset, diagnosis was confirmed by DPT in 32 (24\%) of the 132 subjects with a history of previous immediate reactions and in $8(9 \%)$ of the 87 who reported nonimmediate reactions $(p<0.001)$.

Among patients with confirmed NSAID HS, all the different clinical phenotypes proposed by the EAACI Drug Allergy Interest Group classification could be found. The most frequent phenotypes were NSAID-induced urticaria/angioedema (NIUA) in $24(50 \%)$ patients and single-NSAID-induced urticaria/angioedema or anaphylaxis (SNIUAA) in $16(33 \%)$ patients. Four patients (8\%) were classified as NSAID-exacerbated respiratory disease (NERD), 3 (6\%) as NSAID-exacerbated cutaneous disease (NECD), and 1 as a single-NSAID-induced delayed HS reaction (SNIDR).

The characteristics of the patients for whom an HS diagnosis was either confirmed or excluded are presented in Table 5. There was a significant difference between the 2 groups concerning reaction onset $(p<0.001)$, clinical manifestations on first reaction $(p<0.001)$, and the number of previous reactions $(p<0.01)$. No significant differ- 
Table 6. Predictors of an NSAID HS diagnosis according to a stepwise logistic regression analysis

\begin{tabular}{lrrl}
\hline Independent variables tested & OR & \multicolumn{1}{l}{$95 \%$ CI } & $p$ value \\
\hline Type of reaction (immediate) & 11.87 & $3.07-45.84$ & $<0.001$ \\
Manifestations (only cutaneous) & 0.04 & $0.002-0.797$ & $<0.05$ \\
Number of reactions $(\geq 2)$ & 11.76 & $2.20-62.5$ & $<0.05$ \\
\hline
\end{tabular}

Type of reaction: immediate or nonimmediate. Manifestations: only cutaneous or others. Number of previous reactions: $\geq 2$ or 1 .

ences between groups were found considering gender, age, atopy, or self-reported reactions to other drugs.

A stepwise binary logistic analysis was performed, involving only those patients with conclusive results, in order to predict NSAID HS. Age, gender, reaction onset, clinical presentation on first reaction, number of previous reactions, atopy, asthma/rhinitis or chronic urticaria, and reactions to other drugs were tested as predictors. Potential confounding factors were adjusted. Multivariate analysis revealed that patients with immediate reactions have a higher risk of NSAID HS than those with nonimmediate reactions (OR 11.87; 95\% CI 3.07-45.84). Patients with $\geq 2$ previous reactions also have a higher risk of NSAID HS (OR 11.76; 95\% CI 2.2-62.5). In contrast, patients with only cutaneous manifestations have a lower risk of having confirmed NSAID HS (OR 0.04; 95\% CI 0.0020.797) (Table 6).

When comparing the patients with NIUA $(n=24)$ and SNIUAA $(n=16)$, the 2 more frequent phenotypes in our sample, there were no significant differences concerning the presence of atopy.

\section{Discussion}

We present a series of 227 adult patients with a suggestive history of NSAID HS. As described by other authors, there was an overall female predominance $[3,18,19,29$, 30]; this has also been reported with other drugs, but when considering NSAIDs, it can be related to higher NSAID consumption among women [31-33].

About one-third of the patients in our population were atopic, similar to the proportion of atopic patients referred to in other studies [34, 35].

In this series, acetylsalicylic acid was the most suspected NSAID (34\%) involved, as reported by other authors, i.e. Sánchez-Borges et al. [13] (40\%), Caimmi et al. [20] (39\%), and Nissen et al. [30] (40\%). However, some stud-

Hypersensitivity Reactions to NSAIDs among Adults ies indicate that, nowadays, acetylsalicylic acid is not the most common drug involved in HS, and they refer to propionic acid derivatives, i.e. ibuprofen [3] and metamizole [35] (which rank as 2nd and 5th in our study), as the most common culprits. Almost one-third (30\%) of the patients had already had $>3$ reactions before the assessment, leading us to think that more effort has to be made to increase the awareness of the problem of NSAID HS. In our sample, in confirmation of previous studies, immediate reactions were the more frequent and urticaria/angioedema was the most common presentation $[3,29,30]$.

In agreement with other published results [34, 36], ST with pyrazolones proved to be a useful diagnostic tool, confirming the diagnosis in $8 / 10$ patients tested, although the DPT remains the gold standard for the diagnosis of NSAID HS.

Diagnosis was confirmed in $21 \%$ of the patients, ruled out in $28 \%$, and considered nonconclusive in $51 \%$ (where DPT with the culprit drug was not performed and the clinical history alone was considered unreliable). The confirmation rate that we found is similar to that described by other authors, i.e. Nissen et al. [30] (26\%) and Viola et al. [34] (22\%), but higher rates have been described when more selected populations are analyzed $[29,37]$.

We found, as did other authors [29,37], that the number of previous reactions is a risk factor for diagnostic confirmation. However, some studies show that a clinical history can be misleading even if based on several previous suspected HS episodes or previous anaphylaxis [30, 34, 38]. Weak COX-1 inhibitors, like paracetamol, meloxicam, and nimesulide, usually considered safe alternatives, were frequently involved in the positive DPTs (i.e. in 63\%). Therefore, like other researchers, we recommend a DPT to provide an assurance of tolerance before prescribing these drugs for patients with suspected NSAID HS [13, 19, 39, 40].

In this work, urticaria/angioedema was the most common manifestation in patients with confirmed NSAID HS (in 52\%), as previously described in the literature [3, $12,13,41,42]$. Similar to the results reported by Nissen et al. [30], who had a good degree of agreement when comparing the symptoms of the primary reaction with those induced by the DTP ( $67 \%$ of the cases had full agreement and $23 \%$ had partial agreement), we found a fair agreement between the initial clinical manifestation and the DPT-induced reactions.

Of the cases finally confirmed as HS, based on previous reactions, previous medical history, and the DPT results, we found NIUA in 24 patients, SNIUAA in 16, NERD in 4 , NECD in 3, and an NSAID-induced delayed HS reac-

Int Arch Allergy Immunol 2016;171:269-275 273 
tion (NIDHR) in only 1 . The predominance of NIUA and SNIUAA phenotypes has also been reported by other working groups [34, 35, 41, 42]. However, this is different from the findings of Nissen et al. [30], who described NECD as the most frequent, followed by NERD and SNIUAA. As a consequence of the classification itself, the prevalence of the different phenotypes can depend on the prevalence of previous medical conditions in the studied population.

Research has shown that up to $40 \%$ of NSAID HS reactions are selective $[12,13,20,34,35,41]$, and our results are in line with this findings.

There is still controversy about the importance of clinical history data and their predictive value. Our results, like those of other studies $[29,34,37]$, showed that patients with a previous immediate reaction and those who report $\geq 2$ previous reactions have a greater chance of having their diagnosis confirmed.

On the other hand, we could not corroborate reports from other authors concerning the influence of gender or atopy as a risk factor $[2,13,23,24,28-30,34,41]$. Our data are, however, similar to some other published results $[34,37,43]$. Discrepancies may be due to the characteristics of the populations analyzed, e.g. underlying diseases, or could be linked to the low number of patients with a final confirmed HS, so larger studies would be useful to better clarify this point.

\section{Conclusion}

In this multicenter study, we analyzed a sample of 227 patients evaluated for suspicion of NSAID HS. There was an overall female predominance. Acetylsalicylic acid was the drug most often involved in the reactions, and isolated immediate cutaneous symptoms were the most common. STs and DPTs enabled an HS diagnosis in $21 \%$ of the patients, and ruled it out in $28 \%$. NIUA and SNIUA were the most frequent phenotypes encountered among patients with a confirmed diagnosis. The logistic regression analysis showed that gender and atopy were not significant risk factors for HS confirmation. The probability of a final HS diagnosis depended on the number of previous reactions, the clinical manifestations, and the time interval between drug intake and reaction.

\section{Acknowledgements}

We thank João Firmino-Machado from the Western Oporto Public Health Department for his important support in the statistical analysis.

\section{Disclosure Statement}

No financial support has been attributed.

\section{References}

1 Aagaard L, Strandell J, Melskens L, Petersen PS, Holme Hansen E: Global patterns of adverse drug reactions over a decade: analyses of spontaneous reports to VigiBase ${ }^{\mathrm{TM}}$. Drug Saf 2012;35:1171-1182.

2 Gomes ER, Demoly P: Epidemiology of hypersensitivity drug reactions. Curr Opin $\mathrm{Al}-$ lergy Clin Immunol 2005;5:309-316.

3 Doña I, Blanca-Lopez N, Torres MJ, GarciaCampos J, Garcia-Nuñez I, Gómez F, Salas M, Rondon C, Canto MG, Blanca M: Drug hypersensitivity reactions: patterns of responses, drug involved and temporal variation in a large series of patients evaluated. J Investig Allergy Clin Immunol 2012;22:363-371.

4 Kurt E, Demir AU, Cadirci O, Yildirim H, Pinar Eser T: Immediate-type drug hypersensitivity and associated factors in a general population. Allergol Immunopathol (Madr) 2011;39:27-31.
5 Blanca-López N, Doña I, Perkins JR, Canto G, Cornejo-García JA, Blanca M: Multiple nonsteroidal anti-inflammatory drug-induced cutaneous disease: relevance, natural evolution and relationship with atopy. Int Arch Allergy Immunol 2014;164:147-148.

6 Settipane RA, Constantine HP, Settipane GA: Aspirin intolerance and recurrent urticaria in normal adults and children. Epidemiology and review. Allergy 1980;35:149-154.

7 Erbagci Z: Multiple NSAID intolerance in chronic idiopathic urticaria is correlated with delayed, pronounced and prolonged autoreactivity. J Dermatol 2004;31:376-382.

8 Jenkins C, Costello J, Hodge L: Systematic review of prevalence of aspirin induced asthma and its implications for clinical practice. BMJ 2004;328:434.

9 Kim JE, Kountakis SE: The prevalence of Samter's triad in patients undergoing functional endoscopic sinus surgery. Ear Nose Throat J 2007;86:396-399.
10 Karakaya G, Celebioglu E, Kalyoncu AF: Non-steroidal anti-inflammatory drug hypersensitivity in adults and the factors associated with asthma. Respir Med 2013;107:967974

11 Asero R, Bavbek S, Blanca M, Blanca-Lopez N, Cortellini G, Nizankowska-Mogilnicka E, Quaratino D, Romano A, Sanchez-Borges M, Torres-Jaen MJ: Clinical management of patients with a history of urticaria/angioedema induced by multiple NSAIDs: an expert panel review. Int Arch Allergy Immunol 2013;160: 126-133.

12 Quiralte J, Blanco C, Castillo R, Delgado J, Carrillo T: Intolerance to nonsteroidal antiinflammatory drugs: results of controlled drug challenges in 98 patients. J Allergy Clin Immunol 1996;98:678-685.

13 Sánchez-Borges M, Capriles-Hulett A: Atopy is a risk factor for non-steroidal anti-inflammatory drug sensitivity. Ann Allergy Asthma Immunol 2000;84:101-106. 
14 Gomes E, Cardoso MF, Praça F, Gomes L, Mariño E, Demoly P: Self-reported drug allergy in a general adult Portuguese population. Clin Exp Allergy 2004;34:1597-1601.

15 Rebelo Gomes E, Fonseca J, Araujo L, Demoly P: Drug allergy claims in children: from self-reporting to confirmed diagnosis. Clin Exp Allergy 2008;38:191-198.

16 Faria E, Rodrigues-Cernadas J, Gaspar A, Botelho C, Castro E, Lopes A, Gomes E, Malheiro D, Cadinha S, Campina-Costa S, Neto M, Sousa N, Rodrigues-Alves R, Romeira A, Caiado J, Morais-Almeida M; Portuguese Society of Allergology and Clinical Immunology; Drug Allergy Interest Group: Drug-induced anaphylaxis survey in Portuguese Allergy Departments. J Investig Allergol Clin Immunol 2014;24:40-48.

17 Stevenson DD, Sanchez-Borges M, Szczeklik A: Classification of allergic and pseudoallergic reactions to drugs that inhibit cyclooxygenase enzymes. Ann Allergy Asthma Immunol 2001;87:177-180.

18 Quiralte J, Blanco C, Delgado J, Ortega N, Alcntara M, Castillo R, Anguita JL, Sáenz de San Pedro B, Carrillo T: Challenge-based clinical patterns of 223 Spanish patients with nonsteroidal anti-inflammatory-drug-inducedreactions. J Investig Allergol Clin Immunol 2007;17:182-188.

19 Kowalski ML, Makowska JS, Blanca M, Bavbek S, Bochenek G, Bousquet J, Bousquet P, Celik G, Demoly P, Gomes ER, Niżankowska-Mogilnicka E, Romano A, Sanchez-Borges M, Sanz M, Torres MJ, De Weck A, Szczeklik A, Brockow K: Hypersensitivity to nonsteroidal anti-inflammatory drugs (NSAIDs) - classification, diagnosis and management: review of the EAACI/ENDA(\#) and GA2LEN/HANNA*. Allergy 2011;66: 818-829.

20 Caimmi S, Caimmi D, Bousquet PJ, Demoly P: How can we better classify NSAID hypersensitivity reactions? Validation from a large database. Int Arch Allergy Immunol 2012; 159:306-312.

21 Cavkaytar O, Arik Yilmaz E, Karaatmaca B, Buyuktiryaki B, Sackesen C, Sekerel BE, Soyer O: Different phenotypes of non-steroidal anti-inflammatory drug hypersensitivity during childhood. Int Arch Allergy Immunol 2015; 167:211-221.

22 Kowalski ML, Asero R, Bavbek S, Blanca M, Blanca-Lopez N, Bochenek G, Brockow K, Campo P, Celik G, Cernadas J, Cortellini G, Gomes E, Niżankowska-Mogilnicka E, Romano A, Szczeklik A, Testi S, Torres MJ, Wöhrl S, Makowska J: Classification and practical approach to the diagnosis and management of hypersensitivity to nonsteroidal anti-inflammatory drugs. Allergy 2013;68: 1219-1232.

23 Aberer W, Bircher A, Romano A, Blanca M, Campi P, Fernandez J, Brockow K, Pichler WJ, Demoly P; European Network for Drug Allergy (ENDA); EAACI Drug Allergy Inter- est Group: Drug provocation testing in the diagnosis of drug hypersensitivity reactions: general considerations. Allergy 2003;58:854863.

24 Nizankowska-Mogilnicka E, Bochenek G, Mastalerz L, Swierczynska M, Picado C, Scadding G, Kowalski ML, Setkowicz M, Ring J, Brockow K, Bachert C, Wöhrl S, Dahlén B, Szczeklik A: EAACI/GA2LEN guideline: aspirin provocation tests for diagnosis of aspirin hypersensitivity. Allergy 2007;62:1111-1118.

25 Sampson HA, Muñoz-Furlong A, Campbell RL, Adkinson NF Jr, Bock SA, Branum A, Brown SG, Camargo CA Jr, Cydulka R, Galli SJ, Gidudu J, Gruchalla RS, Harlor AD Jr, Hepner DL, Lewis LM, Lieberman PL, Metcalfe DD, O'Connor R, Muraro A, Rudman A, Schmitt C, Scherrer D, Simons FE, Thomas S, Wood JP, Decker WW: Second symposium on the definition and management of anaphylaxis: summary report - Second National Institute of Allergy and Infectious Disease/Food Allergy and Anaphylaxis Network Symposium. J Allergy Clin Immunol 2006;117:391397.

26 Muraro A, Roberts G, Clark A, Eigenmann PA, Halken S, Lack G, Moneret-Vautrin A, Niggemann B, Rancé F; EAACI Task Force on Anaphylaxis in Children: The management of anaphylaxis in childhood: position paper of the European Academy of Allergology and Clinical Immunology. Allergy 2007;62:857871.

27 Brockow K, Garvey LH, Aberer W, Atanaskovic-Markovic M, Barbaud A, Bilo MB, Bircher A, Blanca M, Bonadonna B, Campi P, Castro E, Cernadas JR, Chiriac AM, Demoly P, Grosber M, Gooi J, Lombardo C, Mertes PM, Mosbech H, Nasser S, Pagani M, Ring J, Romano A, Scherer K, Schnyder B, Testi S, Torres M, Trautmann A, Terreehorst I: Skin test concentrations for systemically administered drugs - an ENDA/EAACI Drug Allergy Interest Group position paper. Allergy 2013; 68:702-712.

28 Cohen J: The $t$ test for means; in: Analysis for the Behavioral Sciences, ed 2. New Jersey, Lawrence Erlbaum Associates, 1988, pp 1974.

29 Blanca-Lopez N, Torres MJ, Doña I, Campo P, Rondón C, Seoane Reula ME, Salas M, Canto G, Blanca M: Value of the clinical history in the diagnosis of urticaria/angioedema induced by NSAIDs with cross-intolerance. Clin Exp Allergy 2013;43:85-91.

30 Nissen CV, Bindslev-Jensen C, Mortz CG: Hypersensitivity to non-steroidal anti-inflammatory drugs (NSAIDs): classification of a Danish patient cohort according to EAACI/ ENDA guidelines. Clin Transl Allergy 2015;5: 10.

31 Helin-Salmivaara A, Klaukka T, Huupponen R: Heavy users of non-steroidal anti-inflammatory drugs: a nationwide prescription database study in Finland. Eur J Clin Pharmacol 2003;59:477-482.
32 Rasmussen HM, Søndergaard J, Kampmann JP, Andersen M: General practitioners prefer prescribing indicators based on detailed information on individual patients: a Delphi study. Eur J Clin Pharmacol 2005;61:237-241.

33 Grimmsmann T, Himmel W: Polypharmacy in primary care practices: an analysis using a large health insurance database. Pharmacoepidemiol Drug Saf 2009;18:1206-1213.

34 Viola M, Rumi G, Valluzzi RL, Gaeta F, Caruso C, Romano A: Assessing potential determinants of positive provocation tests in subjects with NSAID hypersensitivity. Clin Exp Allergy 2011;41:96-103.

35 Demir S, Olgac M, Unal D, Gelincik A, Colakoglu B, Buyukozturk S: Evaluation of hypersensitivity reactions to nonsteroidal antiinflammatory drugs according to the latest classification. Allergy 2015;70:1461-1467.

36 Couto M, Gaspar A, Piedade S, Arêde C, Menezes M, Sousa MJ, Sousa G, Morais-Almeida M: IgE-mediated metamizole allergy and the usefulness of the cellular allergen stimulation test. Eur Ann Allergy Clin Immunol 2012;44:113-116.

37 Dursun AB, Woessner KA, Simon RA, Karasoy D, Stevenson DD: Predicting outcomes of oral aspirin challenges in patients with asthma, nasal polyps, and chronic sinusitis. Ann Allergy Asthma Immunol 2008;100: 420-425.

38 Rubio M, Bousquet PJ, Gomes E, Romano A, Demoly P: Results of drug hypersensitivity evaluations in a large group of children and adults. Clin Exp Allergy 2012;42:123-130.

39 Celik GE, Erkekol FÖ, Aydın Ö, Demirel YS, Misirligil Z: Are drug provocation tests still necessary to test the safety of COX-2 inhibitors in patients with cross-reactive NSAID hypersensitivity? Allergol Immunopathol (Madr) 2013;41:181-188.

40 Kim YJ, Lim KH, Kim MY, Jo EJ, Lee SY, Lee SE, Yang MS, Song WJ, Kang HR, Park HW, Chang YS, Cho SH, Min KU, Kim SH: Crossreactivity to acetaminophen and celecoxib according to the type of nonsteroidal anti-inflammatory drug hypersensitivity. Allergy Asthma Immunol Res 2014;6:156-162.

41 Dona I, Blanca-Lopez N, Cornejo-Garcia JA, Torres MJ, Laguna JJ, Fernandez J, Rosado A, Rondón C, Campo P, Agúndez JA, Blanca M, Canto G: Characteristics of subjects experiencing hypersensitivity to non-steroidal antiinflammatory drugs: patterns of response. Clin Exp Allergy 2011;41:86-95.

42 Ayuso P, Blanca-López N, Doña I, Torres MJ, Guéant-Rodríguez RM, Canto G, Sanak M, Mayorga C, Guéant JL, Blanca M, CornejoGarcía JA: Advanced phenotyping in hypersensitivity drug reactions to NSAIDs. Clin Exp Allergy 2013;43:1097-1109.

43 Çelik G, Mungan D, Ozer F, Ediger D, Bavbek S, Sin B, Demirel YS, Misırligil Z: Clinical features and atopy profile in Turkish subjects with analgesic intolerance. J Asthma 2002;39: 101-106. 